\title{
O conceito pioneiro de ergonomia de Itiro lida no Brasil
}

\section{The pioneering ergonomic concept of Itiro lida on ergonomics in Brasil}

LÓPEZ GÚERRERO, Ana Sofia; Maestrante em Diseño Industrial; Universidad Nacional Autónoma de México

anasofiagro@gmail.com

BRAGA, Marcos da Costa; Doutor em História Social; FAU USP

bragamcb@usp.br

\section{Resumo}

Uma vez que o trabalho do professor Itiro lida ajudou a preencher uma lacuna na integração da disciplina na área de design, é relevante pesquisar quais foram os fundamentos e as ideias iniciais sob os quais o professor trabalhou a ergonomia para realizar a tarefa pioneira no Brasil de propor uma metodologia de ergonomia aplicada ao contexto nacional. O presente texto busca contribuir para a construção da história do design brasileiro e fornecer informações sobre a relação entre a ergonomia e o design neste país.

Palavras Chave: ergonomia, design, Brasil, Itiro lida.

\begin{abstract}
Once the work of professor Itiro lida helped fill a gap in the integration of the discipline in the area of design, it is relevant to investigate what were the foundations and the initial ideas under which the professor worked the ergonomics to accomplish the pioneering task in Brazil to propose a methodology of ergonomics applied to the national context. The present text seeks to contribute to the construction of Brazilian design history and to provide information on the relationship between ergonomics and design in this country.
\end{abstract}

Keywords: ergonomics, design, Brazil, Itiro lida. 


\section{Introdução}

A ergonomia no Brasil tem sido estudada em diferentes disciplinas, como psicologia, engenharia e design. $\mathrm{Na}$ área de design do produto, seu estudo começou graças ao trabalho pioneiro de alguns personagens; e um deles foi o professor Itiro lida. O professor lida tem sido um personagem fundamental na consolidação da importância do ensino e aplicação da ergonomia na área de design de produto devido as suas diversas ações de ensino, promoção e pesquisa dessa disciplina científica ${ }^{1}$. Neste artigo, estudaremos o conceito de ergonomia sob o qual o professor lida trabalha em sua tese de doutorado e no livro Ergonomia, Notas da sala de aula. A importância de analisar as ideias e as perspectivas de lida em sua tese de doutorado se justifica pelo fato de ser a primeira tese no Brasil sobre a ergonomia do produto [tese na qual estabeleceu uma metodologia ergonômica "com ênfase especial na influência do desenho da pega sobre o desempenho do trabalho" (IIDA, 1971)]. Portanto, é um trabalho pioneiro tanto no campo da engenharia de produtos como no design; onde também é relevante para resgatar a influência dos diferentes personagens que giravam em torno de seu desenvolvimento. Assim, sua tese é uma fonte primária para entender o conceito de ergonomia sob a qual lida trabalha porque é a origem do trabalho que se desenvolverá nas décadas seguintes. Por outro lado, o livro Ergonomia. Notas de aula. é um livro dedicado ao ensino da ergonomia e foi o primeiro livro de ergonomia escrito por um autor brasileiro (SILVA, JCP. e PASCHOARELLI LC., orgs. 2010), e que escreveu junto com seu colega J. Wierzzbicki).

Ao contrário de outros colegas que estudaram o tema da ergonomia fora do país, o professor lida foi formado inteiramente no Brasil recebendo aula e trabalhando com outros personagens importantes dentro da conformação desta disciplina cientifica no país. Esta formação, sem dúvida, o torna um caso especial, uma vez que todo seu pensamento é desenvolvido a partir de um contexto brasileiro, onde sua busca está relacionada com a tentativa de responder às demandas nacionais da época, procurando entender como a Ergonomia poderia ser útil na construção de ferramentas e produtos que facilitem a vida dos trabalhadores.

No momento em que lida escreve sua tese de doutorado, apenas duas décadas tinham se passado desde que a ergonomia tornara-se uma área de pesquisa autônoma (em 1949 fundou-se a International Ergonomics Association IEA e, com ela, a constituição da ergonomia é consolidada como uma disciplina independente com seus próprios métodos e objetivos).

No Brasil, Sérgio Penna Kehl introduz em finais dos anos $1950^{2}$ conteúdos de ergonomia no curso de graduação em engenharia de produção da Escola Politécnica da USP, que na época eram chamados de engenharia humana (MORAES, 2013). Em 1965, nesse curso havia uma disciplina de engenharia e métodos e outra de produtos, processos e instalações industriais (IIDA, 2017 e 2015) nas quais a engenharia humana era um componente do projeto de produto. A reflexão sobre essa

\footnotetext{
1 Definição da IEA: Ergonomics (or human factors) is the scientific discipline concerned with the understanding of interactions among humans and other elements of a system, and the profession that applies theory, principles, data and methods to design in order to optimize human well-being and overall system performance. http://www.iea.cc/whats/index.html consultado em fevereiro 2018.

${ }^{2}$ Vários autores dizem que a ergonomia foi introduzida em 1960 na disciplina de projeto de produto da Politécnica, que começou a existir em 1959. Mas Moraes tem uma entrevista com o próprio Kehl na qual ele diz que foi por cerca de 1958 que leu o 10 livro: Human Engineering, do McCormick, recém-lançado nos Estados Unidos e logo depois teria introduzido a engenharia humana no curso
} 
área de estudos estava apenas começando.

O objeto de estudo deste artigo é o conceito e as ideias iniciais de ergonomia para Itiro lida, e o objetivo principal será identificar e compreender esse conceito durante os primeiros anos que lida trabalhou como professor e como aluno de doutorado.

O recorte geográfico será especificamente em São Paulo e Rio de Janeiro, devido a ser nesses estados onde o professor se desenvolveu como aluno, professor e profissional na área de ergonomia aplicada ao design do produto e nas instituições Escola Politécnica da Universidade de São Paulo, EPUSP, e na Escola Superior de Desenho Industrial, ESDI.

O recorte temporal sobre o qual vamos trabalhar abrange de 1961, ano em que começa seus estudos de graduação, até 1973, ano em que publica o livro de Ergonomia. Notas sobre aulas. Durante esse período lida se forma em engenharia de produção pela Escola Politécnica da USP em 1965, faz simultaneamente o curso de Física na mesma universidade, e em 1971, termina o doutorado defendendo a tese sobre ergonomia do manejo.

O período que será analisado corresponde as primeiras concepções de ergonomia sob a qual lida trabalhou, aconselhou, deu aulas e escreveu seu livro e sua tese, e no qual também começa a influenciar o campo do design.

O presente texto busca contribuir para a construção da história do design brasileiro por meio do estudo sobre a relação inicial entre a ergonomia e o campo do design no Brasil.

\section{Métodos e referencial teórico}

A pesquisa se insere no domínio da Historia das ideais que, como outras áreas da História, apresenta potencial para produzir conhecimento histórico para determinados temas de investigação sobre a possibilidade das ideias como objeto de estudo histórico. Sobre essa possibilidade Silva (2015) destaca que há duas leituras, que ao nosso entendimento podem ser complementares:

\footnotetext{
"Uma primeira, como proposição ontológica, que afirma a existência "real" das ideias na história no sentido de matéria do conhecimento histórico, e uma segunda, como proposição epistemológica, que realça a validade de certo tipo de conhecimento histórico no qual as ideias constituem seu objeto de estudo." (SILVA, 2015 p.7)
}

Para o presente estudo nos referenciamos em LaCapra (apud SILVA, 2015), que propõe uma pesquisa em relação a diferentes contextos onde o meio social afeta diretamente a ideia a ser estudada. Ou seja, ele propõe traçar uma história intelectual em relação a uma história social, onde há uma correspondência entre os textos e os contextos.

Esta abordagem, de acordo com LaCapra pode ser feita a partir de seis casos, mas em nossa análise usaremos apenas 4 deles: o primeiro seria tentar encontrar as intenções do autor nos textos, ou seja, quais são as intenções de Itiro lida nos textos que escreveu; o segundo seria a partir de um estudo biográfico do autor, onde poderíamos perguntar como a biografia explica as ideias propostas, desse modo corresponderia aqui em observar a relação entre a vida profissional de lida e os textos em questão, procurando encontrar as motivações do autor; uma terceira abordagem seria baseada na relação entre sociedade e textos, ou seja, um diálogo entre o texto e o meio social em que foi gerado ou com o qual conversa, que em nosso estudo seria indagar quais 
foram as condições que propiciaram possibilidades para desenvolver suas ideias dentro da área do design ou com que processo social o conceito de ergonomia de lida dialoga; e, finalmente, a relação do texto com o corpus de textos do próprio escritor, onde uma relação será feita entre os textos que ele escreveu e as entrevistas que ele deu para assim abrir uma discussão sobre a unidade do conceito que desenvolve ou, em vez disso, encontrar perspectivas diferentes em variadas ideias.

Uma vez que o escopo a ser analisado é relativo a um período específico, não seria suficiente para incluir nos objetivos do presente trabalho a identificação de uma continuidade ou descontinuidade ou mesmo uma "ruptura epistemológica" no pensamento de lida.

Nossa pesquisa é feita a partir da abordagem geral da micro-história (BARROS, 2007) no que concerne a ênfase nos dados obtidos em fontes primárias, na delimitação dos recortes temporal e geográfico e na escala de observação do campo do Design. Os métodos de entrevista são aqueles preconizados pela História Oral (NEVES, 2003). As principais fontes foram os textos de lida, as entrevistas que concedeu à presente pesquisa e à terceiros.

\section{Itiro lida : referentes e antecedentes e o desenvolvimento de um conceito de ergonomia.}

Seu contato com a ergonomia começou com o curso de graduação em Engenharia de Produção na USP, especificamente nas aulas de Engenharia e Métodos e da disciplina Produtos, Processos e Instalações Industriais, ambas ministradas pelo Professor Sérgio Augusto Penna Kehl, que mais tarde seria o seu orientador do trabalho final de graduação. Em uma entrevista concedida para a Associação Brasileira de Ergonomia, ABERGO (MORAES, 1989), Itiro esclarece: "Essa disciplina anual começava com projeto de um produto, onde Kehl apresentava algumas aulas de Ergonomia (era chamada de Fatores Humanos). Depois, elaborávamos os métodos de fabricação desse produto e o respectivo projeto da fábrica (plant layout) para produzi-lo." (IIDA in MORAES, 1989).

Mais tarde, em 1965, trabalhou na Philips, onde completou seu projeto final de graduação: uma organização de linha de produção de produtos eletrônicos (IIDA, 2015). lida verificou que esta empresa deu grande importância à ergonomia (MORAES, 1989). Lá, lida ajudou a fazer uma pesquisa antropométrica dos trabalhadores para adaptar as dimensões das ferramentas de trabalho que até então eram baseadas em medidas holandesas, o que significava muitos inconvenientes para os trabalhadores brasileiros nas linhas de montagem.

O professor lembra que, na Philips, tinha manuais de procedimentos para diferentes assuntos, e que na área de organização e métodos, havia uma publicação chamada Vademecum Ergonomics in Industry, de F. Kellermann, P. van Wely e P. Willems, publicado em 1963 pela Biblioteca Técnica Philips, em holandês, francês, alemão e inglês. Este livro era um manual simples e prático de recomendações para projetos de locais de trabalho (IIDA, 2017).

Por outro lado, a Associação Brasileira de Design Industrial, ABDI, foi outro espaço importante no contato com a ergonomia. Lá conheceu algumas pessoas que já demonstravam interesse nesta disciplina. Um deles foi Professor Bergmiller, pioneiro da ESDI e ex-aluno da escola de design da cidade de UIm, Alemanha. Bergmiller ministrava aulas de Projeto de Produto, onde ensinou alguns temas de ergonomia e aplicações de ergonomia ao projeto de produtos, 
direcionados, principalmente, ao desenho de alças (IIDA, 2017). Em 1966, o professor Bergmiller convidou Itiro para participar de suas aulas na ESDI. Em 1971, lida defendeu a tese intitulada Ergonomia do Manejo para obtenção do título de doutorado na USP e assim se tornou o primeiro doutor em engenharia da USP (IIDA, 2017).

Embora não seja muito claro como ele escolheu o tema central de sua tese de doutorado por um lado, ele afirma que o tópico de pesquisa é retirado de um artigo em uma revista que ele encontrou na biblioteca da ESDI, onde havia uma coleção de revistas de design e onde ele descobriu um pequeno artigo (1 página apenas) sobre projetos de chaves de fenda; e, por outro lado, ele afirma que recebeu a sugestão inicial de seu tema de doutoramento de Karl Heinz Bergmiller - não há dúvida porém de que o professor Bergmiller foi um importante referente para Itiro.

Em sua tese de doutorado, lida trabalhou em uma metodologia de pesquisa para examinar os fatores humanos que influenciam o desempenho do uso de ferramentas. $O$ estudo da chave de fenda - um exemplo de uma ferramenta manual - foi um pretexto para poder trabalhar com essa metodologia, uma vez que a mesma poderia ser adaptada a outras ferramentas e circunstâncias de uso.

lida reconhece que durante seu doutorado foi praticamente autodidata em termos de ergonomia. Ele não podia ser guiado pelo professor Khel, já que o docente só tinha um diploma de graduação em engenharia. Foi então que sua orientação acabou sob a responsabilidade do professor Max Barcellos Correa, professor que ensinava pesquisa operacional e que realmente não tinha muito conhecimento sobre ergonomia (IIDA, 2017). No entanto, havia outros professores como Carolina M. Bori, do Instituto de Psicologia da USP, que co-dirigiram seu trabalho; neste caso, foi a partir da abordagem experimental com sujeitos humanos que a psicologia experimental tem um impacto considerável em seu trabalho, principalmente na construção de uma metodologia para experimentação com seres humanos vivos.

De 1966 a 1971, Itiro lida foi professor na USP. Ele começou sua carreira docente graças a Sergio Khel, professor e orientador de seu trabalho de graduação, que indicou lida para ser contratado como seu professor assistente na EPUSP depois que ele se formou em 1966. Mais tarde, Itiro lida assume várias disciplinas, incluindo Tempos e Métodos. Ele também organizou um Laboratório Didático em Métodos, com a ajuda de Miguel Cezar Santoro. (IIDA, 2017).

lido relata (IIDA, 2017) que, quando começou como professor assistente na EPUSP, introduziu o ensino da ergonomia e que uma das dificuldades que enfrentou foi a dificuldade em obter material bibliográfico na época, já que geralmente os professores que escreviam, e seriam referências na época, reproduziam seus textos em forma de apostilas impressas em mimeógrafos. Diante dessa falta de bibliografia, lida decidiu escrever um material dedicado à ergonomia, que mais tarde foi transformado no livro 'Ergonomia. Notas de aula', escrito em co-autoria com Henri Wierzbicki, publicado pela Faculdade de engenharia industrial, FEl, São Bernardo do Campo. Com o título atual Ergonomia: Projeto e Produção foi publicado pela Editora Blucher em uma primeira edição surgida em 1990 (12 mil exemplares vendidos), e em uma segunda edição, em 2005 (17 mil exemplares) e na terceira, em 2016, em co-autoria com a designer e pesquisadora Lia Buarque M. Guimarães. (IIDA, 2017).

Em 1971 lida ministrou aula na ESDI. Foi professor na escola carioca apenas por um ano, sendo substituído mais tarde pelos professores Pedro Luiz Pereira e Silva Steinberg. No entanto, 
ele continuou vinculado a ESDI, orientando o trabalho de graduação de alguns estudantes e participando de exames profissionais. E também em 1971 inicia a docência no curso de graduação em Engenharia de Produção da Escola de Engenharia da Universidade Federal do Rio de Janeiro e do curso de pós-graduação em Engenharia de Produção, cargo que ocupou até 1975. Durante esse período, o professor também desenvolveu vários projetos de pesquisa em ergonomia com colaboradores como João Bezerra (de quem foi professor e orientador de mestrado), Luiz Blank, Freddy van Camp e outros designers.

O estudo que lida faz na sua tese de doutorado é uma análise científica de métodos e ferramentas de trabalho para melhorá-los a partir de uma abordagem ergonômica. Com a ajuda da fisiologia, anatomia e psicologia, deixa para trás a ideia do estudo do trabalho humano a partir de uma perspectiva taylorista em relação aos tempos.

A metodologia que desenvolve parte da verificação do projeto de ferramentas manuais e sua interferência no desempenho do trabalho, ou seja, da avaliação do desempenho no uso de ferramentas. Itiro estava interessado em verificar como o projeto de ferramentas manuais poderia interferir no desempenho do trabalho (IIDA 2017). Foi então que ele usou as chaves de fenda como um objeto de estudo porque, dada a existência de diferentes modelos, ele poderia avaliar o desempenho em diferentes configurações da forma em relação à função.

Como já mencionado, lida teve contato com a ergonomia através dos fatores humanos nas aulas de Sergio Khel. Nesse sentido, chama a atenção que, embora sejam mais tarde reconhecidos como sinônimos, lida se concentrará no conceito de ergonomia e não no de fatores humanos, entendendo ergonomia e fatores humanos como duas abordagens com diferenças em conteúdos e origens:

\begin{abstract}
"Havia também grande diferença de conteúdo entre eles. Na Europa, as pesquisas eram direcionadas principalmente para avaliar os fatores fisiológicos do esforço. Nos EUA, eram direcionadas principalmente para as pesquisas militares e espaciais, relacionando-se principalmente para os aspectos do desempenho homem-máquina. Desse modo, no princípio, as pesquisas em ergonomia nos EUA eram chamados pejorativamente de "knobs e mostradores". Nas décadas seguintes, com crescente ampliação dos objetivos das pesquisas e a troca de informações, esses dois termos passaram a ser usados como sinônimos. Tanto é que o grande Handbook organizado por Gavriel Salvendy tem o título de Human Factors and Ergonomics". (IIDA, 2017)
\end{abstract}

No entanto, a formação de graduação de lida e a abordagem de ergonomia de sua tese foram de uma perspectiva anglo-saxônica, que depois da viagem que Murell $^{3}$ e uma equipe de pesquisadores fizeram aos Estados Unidos no ano 1956 os métodos e objetivos tanto da ergonomia como dos fatores humanos foram homogeneizados, criando uma só perspectiva da disciplina.

As abordagens que lida teve no aprendizado dessa disciplina, seja por Kehl, seja por Bergmiller, ou por outros colegas, começam a partir de uma abordagem anglófona à ergonomia, e como aponta Rodrigo Gomes de Almeida: “...encontra-se voltado para os métodos e as tecnologias. O que importa são os aspectos físicos da relação homem-máquina, os quais serão

\footnotetext{
${ }^{3}$ K.F.H. Murrell (1908-1984) foi um dos impulsores mais importantes da ergonomia a nível global e um dos fundadores da Ergonomics Research Society.
} 
dimensionados, discriminados e controlados." (ALMEIDA, 2011: 115)

Apesar disso, lida pretende não limitar seus estudos aos aspectos físicos desta relação, tanto que, no desenvolvimento de sua metodologia, a perspectiva que os estudos da psicologia trazem à ergonomia ocupam um espaço importante na teoria da sua metodologia. Contudo, não considera dentro da metodologia da tese as respostas subjetivas e imprevistas por parte dos trabalhadores ao fazer uso das ferramentas, indicando que são critérios difíceis ou quase impossíveis de quantificar. Ao mesmo tempo, levanta questões interessantes, como as contribuições da biônica e cibernética.

Para lida, a ergonomia é uma ciência e seu objetivo é a adaptação do trabalho ao homem (IIDA, 1971: 07), onde as máquinas complementam e aumentam as capacidades humanas. Funciona a partir de uma avaliação do sistema homem-máquina com critérios para o homem, que diz, são geralmente complexos devido à complexidade natural do ser humano (IIDA, 1971). Sua pesquisa não é dirigida unicamente ou principalmente a avaliação dos fatores fisiológicos do esforço nem o desempenho homem-máquina, mas é uma combinação de ambas preocupações com o objetivo de ajudar a construir um ambiente melhor para os trabalhadores e para a economia nacional :

\footnotetext{
"Resumidamente, podemos dizer que o objetivo da ergonomia é o de aumentar a eficiência do trabalho humano, fornecendo dados para que este trabalho possa ser dimensionado de acordo com as reais capacidades e necessidades do organismo. Ajuda a projetar maquinas adequadas ao uso humano, reduz a fadiga e os desconfortos físicos do trabalhador, diminui o índice de acidentes e ausências no trabalho. Em outras palavras, aumenta a eficiência, reduz os custos e proporciona mais conforto ao trabalhador, contribuindo não só para o bem estar humano, mas também para a economia nacional como um todo" (IIDA, 1971 p.2)
}

É importante lembrar que as propostas de Itiro surgem num certo momento em que há uma política de urgência para incentivar o crescimento industrial. O regime civil-militar que assumiu o governo no Brasil em 1964 - e continuou até 1985 - teve um projeto econômico e industrial de natureza desenvolvimentista que, para implementá-lo, exigia técnicos qualificados. Assim, este governo apoiou os cursos de pós-graduação em engenharia, principalmente na Pontifícia Universidade Católica do Rio de Janeiro, PUC- RJ, e na Coordenação dos Programas de Pós-Graduação e Pesquisa de Engenharia, Coppe / UFRJ que foram fundados na década dos anos 1960 graças à iniciativa do BNDE (IIDA, 2017).

É nesta época que o país começa a sair de um período recessivo e inicia um período conhecido como 'milagre econômico', no qual houve um crescimento industrial e um aumento de consumo para uma parcela da população que formava uma restrita classe média. Em 1971, quando lida conclui sua tese, o Brasil está no meio desse processo que finda em 1973, ano da crise internacional do petróleo.

Do mesmo modo, o estudo realizado por Itiro ocorre em um contexto em que há uma busca por parte da indústria (e conseqüentemente pelos engenheiros e os projetistas) por inserir o trabalhador em um ambiente de trabalho que modifica seu relacionamento com o que ele produz e como ele o produz. Nesse sentido, o professor Itiro, no prólogo de sua dissertação de 1971 ou de vez em quando em alguma entrevista (IIDA, 2017), revela seu compromisso social e ético com o trabalhador, com aquele que usará as ferramentas e para aqueles que sofrem as conseqüências de trabalhar em situações e com ferramentas que não correspondem às condições 
reais das atividades realizadas.

Poderíamos dizer, então, que as pesquisas do professor, partem de uma urgência em entender como melhorar as condições do trabalho por meio do estudo de sua relação com o projeto e a engenharia, tudo isso enquadrado sob a perspectiva de que a solução é ergonômica.

Para Itiro a ergonomia é, sem dúvida, interdisciplinar, isso é algo que não só afirma em seus textos, mas também leva à prática tanto no seu trabalho como professor, como pesquisador e como profissional:

\begin{abstract}
"Várias disciplinas científicas e tecnológicas, formam o arcabouço da ergonomia. Com a anatomia e a fisiologia, aprendemos a estrutura e o funcionamento do corpo humano. A antropométrica das informações sobre as dimensões do corpo. A psicologia experimental procura definir os parâmetros do comportamento humano. A medicina industrial, ajuda a definir as condições de trabalho prejudiciais ao organismo humano. A física e algumas especializações da engenharia fixam as condições com as quais o trabalhador deverá se contentar. Todas estas informações acumuladas nos campos afins do conhecimento humano, formam a base da ergonomia. A ergonomia as utiliza para fazer as suas próprias pesquisas para determinar o desempenho humano no trabalho, tendo já uma sistemática própria para isto." (IIDA, 1978 p.1)
\end{abstract}

E em outro momento ele afirma: "A ergonomia, tendo um carácter (sic) essencialmente interdisciplinar estava destinada a superar muitas barreiras entre profissionais de diversas formações, a favor de um esforço integrado no sentido de melhorar as condições do trabalho humano." (IIDA 1971 p.2)

Essa ideia de interdisciplinaridade do campo, não é originalmente de lida. Já para Sérgio Khel, professor de lida em seu projeto final de graduação, a psicologia era uma área importante no estudo de fatores humanos. De acordo com um artigo publicado em 1964 (para a revista 0 Dirigente Industrial de novembro de 1964, p.106-114) para Kehl havia 3 fatores na consideração da medida geral de eficiência no projeto do produto: o fator humano, o fator de produção e o do comércio.

Quanto ao fator humano, Khel diz que apenas dois aspectos o influenciam: o fisiológico, que tem a ver com a massa e força de um corpo; e o psicológico, que envolve reações psíquicas que vão do ódio ao amor, e às reações provocadas pelo ruído e pelas cores (O DIRIGENTE INDUSTRIAL, 1964 p.106). Baseada em depoimentos de Kehl, a reportagem da revista definia a engenharia humana como "disciplina intermediária" que "utiliza elementos das mais variadas fontes" (O DIRIGENTE INDUSTRIAL, 1964 p. 107). Neste breve texto, não só a influência de Khel em Itiro pode ser verificada em termos da importância da incorporação da psicologia ao estudo de fatores humanos, mas também de uma perspectiva interdisciplinar do estudo.

No entanto, e apesar desta influência, lida realiza uma própria interpretação dos fatores humanos e decide trabalhar com a ergonomia, onde o estudo proposto ultrapassa as questões físicas, musculares e antropométricas, envolvendo subjetividade

Finalmente, em relação ao livro Ergonomia. Notas de aula, chama a atenção a ênfase que ele faz sobre os diferentes fenômenos relacionados ao estudo do trabalho e o desenvolvimento e implementação de ergonomia para contribuir com essa atividade, referindo-se à história do desenvolvimento tecnológico em relação ao crescimento econômico, um assunto que em poucos livros de ergonomia o espaço é dedicado. 
Ou seja, ele faz um comentário geral (como precedente dos estudos ergonômicos), sobre as mudanças nos métodos e ferramentas de trabalho, principalmente durante o século XVIII, quando uma grande parte da população mundial deixa o campo para trabalhar nas cidades, dando uma visão histórica do fenômeno do trabalho dentro das fábricas. ${ }^{4}$

\section{Considerações finais}

O valor das contribuições de lida está na busca da construção de métodos e discursos sem antecedentes no país, porque embora no momento em que lida escreve sua tese de doutorado a ergonomia já tenha algumas décadas de estudo tanto na Inglaterra, nos Estados Unidos e em outros países, no Brasil muito poucos profissionais dedicavam tempo para estudá-la ou ensiná-la, e muito menos para escrever sobre o assunto.

lida, formado e orientado por professores com diferentes posturas e formações, conseguiu gerar uma ideia de ergonomia e uma metodologia que pretendia responder às demandas nacionais de produção por meio do estudo de ferramentas de acoplamento para trabalhadores brasileiros, tentando com a proposta de um método ergonômico tornar a ergonomia uma ciência útil para diversas áreas.

Não há dúvida de que ambos os professores $\mathrm{Khel}^{5}$ e Bergmiller foram uma forte influência na construção que lida fez da ergonomia focada no design industrial. Cada professor contribuiu com uma perspectiva diferente que lida conseguiu assimilar e interpretar. Por um lado, Khel usou bibliografia produzida nos Estados Unidos (IIDA, 2017) ${ }^{6}$, bibliografia onde a abordagem era feita a partir de fatores humanos com uma perspectiva mais relacionada à engenharia [o termo ergonomia não era usado na Politécnica no momento em que lida fez sua graduação, e sim o termo Human factors (IIDA, 2015)]; por outro lado, Bergmiller formado na escola de Ulm, estava familiarizado com a perspectiva de ergonomia aplicada ao produto a partir do design.

lida procurou atender às necessidades não cobertas pelo profissional brasileiro (designer ou engenheiro) encarregado de construir condições de trabalho em um momento em que, em todos os setores de atividades humanas, o trabalho físico começou a ser substituído por máquinas, um processo que na Europa se iniciou entre o século XIX e inicio do XX, mas que no Brasil vai ocorrer com a industrialização mais consistente iniciada nos anos 1930 e que foi estimulada dos anos 1950 até inicio dos anos 1970. É nestas duas décadas em que há um maior numero de áreas de produção material nas quais o trabalho artesanal é paulatinamente substituído pelo industrial.

Itiro foi pioneiro em muitos assuntos (formado na engenharia, abre uma frente nova na relação entre engenharia, ergonomia e design no Brasil) devido à sua trajetória entre os campos e à suas atividades como orientador e autor. Seu pensamento é parte de uma tradição que entende o ser humano como uma peça em um sistema unitário (sistema homem-máquina). Entretanto, devemos observar que na construção de sua proposta de doutorado há uma aparente contradição por não focar os estudos ergonômicos sobre aspectos fisiológicos e anatômicos levando em

\footnotetext{
4 "A maior parte da literatura sobre o homem e o seu trabalho preocupa-se essencialmente com os fatores econômicos. Recentemente tem surgido publicações sobre a historia da tecnologia, que incluem a ciência do trabalho." (IIDA, 1978 p.4)

${ }^{5}$ Kehl foi designer de varias empresas desde os anos 1960 e foi presidente da ABDI de 1974 até 1976.

${ }^{6}$ Kehl declara que o primeiro livro que leu sobre ergonomia foi Human Engineering, de McCormick, em 1958, lançado nos Estados Unidos ( MORAES, 2013: p. 05)
} 
consideração problemas psicológicos e comportamentais. Ao focar na tese as posições do corpo do trabalhador e os aspectos fisiológicos e anatômicos, não conseguiu naquele momento alcançar no seu estudo sua defesa de ampliar o espectro de análise ergonômica. Em outras palavras, embora defendesse a extensão da ergonomia em termos teóricos, na prática, a tese acabou por se concentrar nos aspectos fisiológicos e anatômicos do ser humano. Porém, isso pode ter sido devido à falta de ferramentas tanto conceituais como tecnológicas para tal empreendimento, ou à falta de equipe especializada e adequada para ajudá-lo neste sentido e pelo fato de que ele desenvolveu seu trabalho praticamente de forma autodidata, sem muitas referências nacionais.

Por outro lado, sua perspectiva social sobre a aplicação da informação que a ergonomia pode fornecer na relação homem-ferramenta / máquina é notória. Podemos verificá-la em várias entrevistas que ele dá e na dedicatória que ele escreve em sua tese de doutorado: "A todos os jovens brasileiros que dependem da força dos seus braços e das habilidades das suas mãos para sobreviver. Que a ergonomia, esta ciência também criança, possa ajudá-los a ter uma vida melhor e mais digna" (IIDA, 1971)

Sobre sua posição na engenharia atrelada à uma perspectiva ergonômica, Itiro a considera diferente do que era comum na época:

\begin{abstract}
“... principalmente por atuar dentro da engenharia de produção, que era praticamente dominado pelo pessoal de métodos quantitativos. Vivia-se numa época de deslumbramento com a pesquisa operacional e acha-se que os métodos matemáticos e estadísticos, ajudados pelos grandes computadores, poderiam resolver todos os problemas. Naturalmente eu era considerado um "estranho no ninho" e só mereci um pouco de respeito devido a seriedade com que fazia as coisas, que geralmente eram bem aceitas pelos alunos. Até a variável humana na produção era quantificada pelo "taylorismo". Esse panorama só começou a mudar nos últimos anos." (IIDA in MORAES, 1989).
\end{abstract}

Não obstante das dificuldades que teve em algum momento, seu trabalho foi bem aceito dentro da academia, provavelmente devido ao reconhecimento da importância desses estudos na produção de ferramentas e objetos, bem como na urgência de mudar a perspectiva de projetação dentro da engenharia e dentro do design de uma cultura racionalista do projeto centrado no produto para uma funcional centrada na relação de uso com o usuário.

Apesar de seu trabalho como pioneiro no campo da ergonomia, lida não se considera ergonomista:

\begin{abstract}
“Em primeiro lugar, não me considero um ergonomista porque esse neologismo implica na existência de um novo tipo de profissão, com interesses corporativos e exclusivistas, com os quais não concordo. A ergonomia, sendo uma área interdisciplinar de conhecimentos, deve estar a serviço de diversos tipos de profissionais, como já me manifestei acima." (IIDA in MORAES, 1989).
\end{abstract}

Mas ele reconhece a importância de que a ergonomia deve ser uma área interdisciplinar, entendendo que essas condições interdisciplinares devem existir para que a área possa se desenvolver.

Para lida, a ergonomia pode contribuir para melhorar a produtividade do trabalho humano e reduzir o desconforto dos trabalhadores. No design, pode ajudar o desenvolvimento de produtos de melhor qualidade. No entanto, ele não concordou quando a ABERGO lançou uma proposta de certificação, porque parecia um movimento corporativista "visando preservar o 
mercado de trabalho".

$\mathrm{Na}$ entrevista realizada para a nossa pesquisa, lida reitera:

\begin{abstract}
"Ainda acho que ergonomia é interdisciplinar e que os conhecimentos básicos de Ergonomia podem beneficiar todos os profissionais que atuam na área do trabalho humano e saúde dos trabalhadores. A meu ver, a principal função da ABERGO, como foi concebida desde o início, é fazer a difusão da ergonomia a todos esses profissionais e não a de defender os interesses classistas." (IIDA, 2017).
\end{abstract}

Desde a década de 1990, a ergonomia despertou grande interesse entre os alunos de diferentes campos, e foi incluída em disciplinas obrigatórias e opcionais tanto em cursos de graduação de engenharia quanto nos de design e tem sido o objeto de estudo principal de muitos grupos de pós-graduação e pesquisa no Brasil.

\title{
5 Referências
}

ALMEIDA, Rodrigo Gomes de. A ergonomia sob a ótica anglo-saxônica e a ótica francesa. VÉRTICES, Campos dos Goytacazes/RJ, v. 13, n. 1, p. 115-126 , jan./abr. 2011

BARROS, José D’Assunção. Sobre a feitura da micro-história. Revistas UFG. OPSIS, vol. 7, no 9, juldez 2007.

IIDA, Itiro, Henri A. J. Wierzzbicki. Ergonomia, notas de aulas. 3.ed. São Paulo: Faculdade de engenharia industrial, 1978.

A ergonomia do manejo. São Paulo, Teses submetida a congregação da escola politécnica da universidade de São Paulo para obtenção do grau de doutor em ciência. 1971.

...Ergonomia. Projeto e produção. 2.ed. São Paulo: Blücher, 1993.

MORAES, Anamaria de. Ergonomia, Ergodesign e Usabilidade: algumas histórias, precursores: divergências e convergências. Ergodesign e HCl. N.1, V. 1, ano 1. Rio de Janeiro: PUC-Rio, 2013.

MORAES, A.; Soares, M. M. Ergonomia no Brasil e no mundo: um quadro, uma fotografia. Rio de Janeiro: Editora Univerta, 1989.

NEVES, Lucilia de Almeida. Memória e História: potencialidades da História Oral. Revista ArtCultura. Uberlândia: Núcleo de Estudos em História Social da Arte e da Cultura da Universidade Federal de Uberlândia, v. 5, n. 6. p. 27-38, janeiro/junho de 2003.

O DIRIGENTE INDUSTRIAL Projeto de produto é arma de competição. O dirigente industrial. São Paulo: Visão, 1964. p.p. 106-114 Novembro 1964.

SILVA, Ricardo Oliveira da. História das Ideias: abordagens sobre um domínio historiográfico. Revista Brasileira de História \& Ciências Sociais - RBHCS Vol. 7 No 13, Julho de 2015. DOI: http://dx.doi.org/10.14295/rbhcs.v7i13.300

SILVA, JCP., and PASCHOARELLI, LC., orgs. A evolução histórica da ergonomia no mundo e seus pioneiros [online]. São Paulo: Editora UNESP; São Paulo: Cultura Acadêmica, 2010. 103 p. Available from SciELO Books. 


\section{Entrevistas}

IIDA, Itiro. Entrevista concedida à Marcos da Costa Braga, em 05 de setembro de 2015, na cidade de Brasília, com 40 minutos de duração.

IIDA, Itiro, entrevista concedida a Ana Sofia López Gúerrero em Dezembro de 2017, por correio eletrônico. 